\title{
Water fluoridation unanimously approved
}

The national conference of Local Dental Committees (LDCs), which represents more than 25,000 NHS dentists working in high street practices, is supporting community water fluoridation in areas of need. A motion applauding those local authorities taking forward water fluoridation was approved unanimously at the conference on 7 June.

The vote is an important milestone for the newly formed Community Water Fluoridation network. The network's role is to make sure that public consultations are informed by scientific evidence and accurate representation of the needs of families in their locality.

LDC members have provided the impetus for the network which is supported by a wide range of dental, medical and health-related organisations. Among them are NHS England, the British Fluoridation Society, the British Dental Association, the British Society of Paediatric Dentistry and the Association of Dental Groups.

Simon Hearnshaw, a dentist who works for Health Education England, and who 害 put forward the motion, said: 'To have this $\because$ kind of unanimous response from dentists highlights just how strongly we all support fluoridation of water and want to see the oral health of our young patients improve.'

Water fluoridation is approved by parliament but since 2012, local authorities which

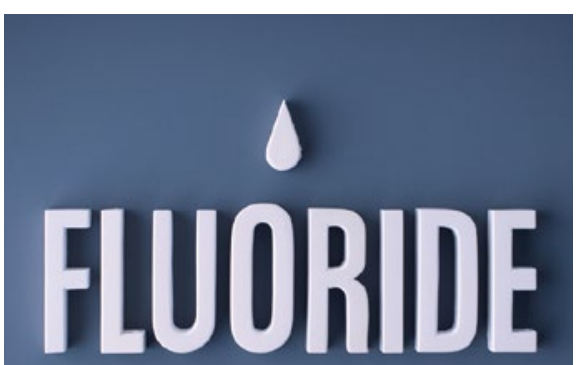

want to implement the public health measure must first carry out a public consultation.

The network is at the ready to put forward dental and medical spokespeople from local communities who will answer questions and describe the dental challenges they are dealing with almost daily and the difference water fluoridation could make. They will be ready to attend events and meetings over the course of the consultations so that there is consistent dental representation.

In 2016-17, more than 42,000 hospital admissions in England were for the extraction of decayed teeth, mostly in very young children, who cannot be treated in general practice, costing more than $£ 50$ million. Areas where water is not fluoridated have a disproportionately higher number of children suffering from dental decay.

Six million people in the UK live in areas where the water supply is fluoridated and a further one third of a million live in areas where the water has naturally occurring fluoride.

Public Health England says fluoridation is an effective and safe public health measure to reduce the prevalence and severity of dental caries, and reduce dental health inequalities.'

\section{References}

1. Public Health England. Water fluoridation. Health monitoring report for England 2018. Executive summary. Available at: https://assets. publishing.service.gov.uk/ government/uploads/system/uploads/attachment_data/ file/692756/EXECUTIVE_SUMMARY_Water_Fluoridation_Health_monitoring_report_for_England_2018_ DR.pdf (accessed 13 June 2019).

\section{Honours, awards, appointments}

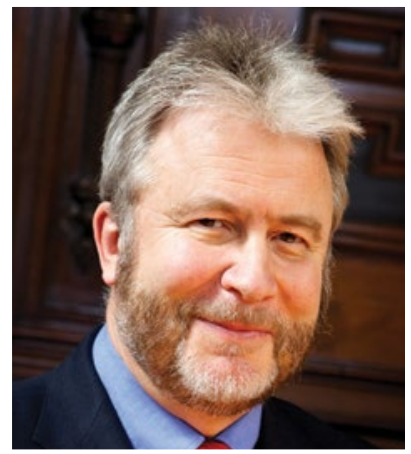

Professor Richard Welbury CBE

\section{CBE}

Professor Richard Welbury (pictured) has been appointed Commander of the British Empire (CBE), the highest of honours, for services to paediatric dentistry, dental education and safeguarding of children.

Professor Welbury is currently Professor of Paediatric Dentistry at the University of Central Lancashire in Preston and Hon
Consultant at North Cumbria University Hospitals Trust and Cumbria Partnership NHS Foundation Trust, but will retire in August.

\section{BEM}

Julie Fountain, Trustee and Programme Co-ordinator of children's dental health charity Teeth Team, has been awarded a British Empire Medal (BEM) for services to dentistry in the Queen's Birthday Honours List. Julie has been a dental nurse for over 22 years and is Head Nurse and Lead Oral Health Educator at 543 Dental Centre in Hull. She has worked tirelessly for Teeth Team over the past nine years to bring the message of dental health to some of the most deprived children in the UK.

Fiona Ellwood has also been awarded the BEM for services to dentistry. Fiona is the patron and executive director of the Society of British Dental Nurses (SBDN) and also chairs the National Oral Health Group. She was lately senior lecturer and external examiner at the University of Chester. She acts as a key opinion leader and is an advisor for oral health education and preventative programmes across the dental arena, as well as infection control and professional practice.

\section{Academic Dean}

Brian Westbury has been appointed as Academic Dean of the Faculty of Forensic and Legal Medicine (FFLM). The FFLM is a charity set up to develop and maintain the highest possible standards of competence and professional integrity in forensic and legal medicine.

In 2018 Dentolegal Advisers were admitted on equal terms with their Medicolegal colleagues. Brian, who is a Senior Dentolegal Adviser at DPL/MPS, was awarded a Fellowship. Brian will act as Dean for all the current members but will also be responsible for encouraging dental members over his three years in office. 